\title{
Ruthenium(II)- bipyridyl with extended $\pi$-system: Improved thermo-stable sensitizer for efficient and long-term durable dye sensitized solar cells
}

\author{
M CHANDRASEKHARAM ${ }^{\mathrm{a}, *}$, G RAJKUMAR $^{\mathrm{c}}, \mathrm{CH}^{\mathrm{S}}$ SRINIVASA RAO ${ }^{\mathrm{a}}, \mathrm{T} \mathrm{SURESH}^{\mathrm{a}}$, \\ P Y REDDYc and Y SOUJANYA ${ }^{\mathrm{b}}$ \\ ${ }^{a}$ Inorganic and Physical Chemistry Division, Indian Institute of Chemical Technology, Uppal Road, Tarnaka, \\ Hyderabad 500 607, India \\ ${ }^{\mathrm{b}}$ Molecular Modelling group, Indian Institute of Chemical Technology, Uppal Road, Tarnaka, \\ Hyderabad 500 607, India \\ ${ }^{\mathrm{c}}$ Aisin Cosmos R\&D Co. Ltd, Nanomaterials Laboratory, Indian Institute of Chemical Technology, \\ Uppal Road, Tarnaka, Hyderabad 500 607, India \\ e-mail: chandra@iict.res.in
}

MS received 6 January 2011; revised 18 May 2011; accepted 19 May 2011

\begin{abstract}
A new extended thermo-stable high molar extinction coefficient bipyridyl ruthenium(II) complex “cis-Ru(4,4'-bis(3,5-di-tert-butylphenyl)-2,2'-bipyridine)(Ln)(NCS $)_{2}$ H101", where $\mathbf{L n}=4,4$ '-dicarboxylic acid-2,2'-bipyridine; was synthesized and characterized by ${ }^{1} \mathrm{H}-\mathrm{NMR}$, FT-IR and ESI-MASS spectroscopes. The H101 sensitized solar cell constructed with an active area of $0.54 \mathrm{~cm}^{2}$ in combination with an ionic liquid electrolyte exhibited broader photocurrent action spectrum with solar-to-electric energy conversion efficiency $(\eta)$ of $5.89\left(J_{\mathrm{SC}}=12.14 \mathrm{~mA} / \mathrm{cm}^{2}, V_{\mathrm{OC}}=690 \mathrm{~V}\right.$, fill factor $\left.=0.699\right)$ under Air Mass (AM) 1.5 sunlight, while the reference 'cis-Ru(4,4'-dinonyl-2,2'-bipyridine)(Ln)(NCS)${ }_{2}$ ', Z907 sensitized solar cell exhibited $\eta$-value of $5.17 \%\left(J_{\mathrm{SC}}=11.93 \mathrm{~mA} / \mathrm{cm}^{2}, V_{\mathrm{OC}}=650 \mathrm{~V}\right.$, fill factor $\left.=0.666\right)$. TGA analysis of $\mathbf{H} 101$ showed extended thermal-stability and under continuous light exposure and aging at $55^{\circ} \mathrm{C}$, the DSSC retained $85 \%$ of its initial $\eta$-value, while under comparable conditions Z Z907 sensitized solar cell retained $88 \%$. As compared to 4,4'-dinonyl-2,2'-bipyridine in $\mathbf{Z} 907$, the new ancillary bipyridyl ligand '4,4'bis(3,5-di-tert-butylphenyl)-2,2'-bipyridine' in H101 shifts the absorption bands remarkably towards blue. The Density Functional Theory (DFT) and Time-Dependent DFT excited state calculations of the new sensitizer show that the first three HOMOs have $2 \mathrm{~g}$ character with sizeable mixing from the NCS ligands with $\pi$-bonding orbitals of 4,4'-bis(3,5-di-tert-butylphenyl)-2,2'-bipyridine. The LUMO is a $\pi^{*}$-orbital localized on the 4,4-dicarboxylic acid-2,2'-bipyridine and higher un-occupied frontier orbitals have $\pi *$-combinations with 4,4'-bis(3,5-di-tert-butylphenyl)-2,2'-bipyridine.
\end{abstract}

Keywords. Dye sensitized solar cells; extended $\pi$-system; thermo-stable; Polypyridyl Ru(II)-sensitizers.

\section{Introduction}

Essentially the source of all forms of energy on all planets in the solar system is coming from the Sun. The energy radiated by the Sun is about 10'000 times the currently needed energy on the Earth. Some of it being reflected back into space, a lot being absorbed by water surfaces, mountains and clouds. The irradiation variations are also moving winds and waves and evaporating water for useful precipitations for the growth of biomass and the river motions by gravity. There is a lot of potential to use all these forms of renewable

*For correspondence energy to cater everyday needs of the human race. Efficient trapping of sunlight and directly converting into electricity has been a challenge over the last few decades. Researchers all over the world are focussing on development of high efficient long-term durable solar cells. In this regard Silicon Solar cells have been well established as highly efficient and their uses are limited to space applications owing to the high cost involved in their manufacture. Recently among thin film photovoltaics, organic solar cells and dye sensitized solar cells gained special attention because of their high photon-to-electricity conversion efficiency, easy fabrication, low cost involved in mass production compared to the traditional photo-electrochemical cells. ${ }^{1-5}$ Among the various components employed 
in the fabrication of DSSC, sensitizer plays a key role in-terms of overall performance. Since Michael Graetzel introduced the first efficient nano-crystalline $\mathrm{TiO}_{2}$ solar cell sensitized with cis-bis(thiocyanato) bis (2,2'-bipyridyl-4,4'-dicarboxylato) ruthenium(II) bis(tetrabutylammonium) (N719), a variety of ruthenium(II) polypyridyl complexes, porphyrins, phthalocyanines and metal free organic sensitizers have been developed. ${ }^{6-17}$ Over the last two decades, there have been considerable interest to improve the overall solarto-electrical energy conversion efficiency $(\eta)$ of the DSSC devices by modifying the structure of sensitizers and varying the other components of the device. For instance, one of the bipyridyl ligand of N719 was substitued with alkoxy styryl, triethyleneoxy (ion coordinating) styryl, tert-butoxy styryl, etc. groups with the concept of increase in the $\pi$-conjugation extension for high molar extinction coefficient dyes or optimizing the DSSC fabrication conditions with suitable electrolyte and favourable texture of the nanocrystaline $\mathrm{TiO}_{2}$ electrodes. ${ }^{16,18-20}$ But long-term device durability is found to be one of the key limitations of DSSC device for outdoor application. The leakage of liquid electrolyte, desorption of loosely anchored dye molecules, and photo-degradation of the dye anchored on $\mathrm{TiO}_{2}$ as well as corrosion of the $\mathrm{Pt}$ counter electrode by the triiodide/iodide couple have been suggested as the factors responsible for limiting the long-term performance of DSSC. To overcome this, new counterelectrode materials, ${ }^{21-23}$ alternative redox couples ${ }^{24-26}$ such as solid state or quasi-solid-state elecrtolytes have been thoroughly studied. In this regard Z907 and K77 dyes showed considerable long term durability with moderate conversion efficiencies. However, achievement of high device conversion efficiency along with long-term durability remains a major challenging task. ${ }^{13,27-36}$ Substituted bipyridines recently attracted special attention for their importance in biological applications as $\mathrm{Zn}^{2+}$ specific fluorescent molecular probes. ${ }^{37-39}$ We developed ruthenium(II) bipyridyl complexes cis-Ru(4,4'-bis(3,5-di-tert-butylstyryl)-2,2'bipyridine $)(\mathbf{L n})(\mathrm{NCS})_{2} \quad$ 'HRD1' and cis-Ru(4,4'bis(2,4,6-trimethylstyryl)-2,2'-bipyridine)(Ln)(NCS $)_{2}$

'HRD2' where $\mathbf{L n}=4,4$ '-dicarboxylic acid-2,2'bipyridine, which have shown good conversion efficiencies along with device durability comparable with K77 sensitized solar cells. ${ }^{40}$ The ruthenium (II) complexes, H112, ${ }^{41}$ PTZ1, ${ }^{42}$ mLBD1 and mLBD2 ${ }^{43}$ developed in our laboratory with $\pi$-conjugation extension also showed moderate efficiency in DSSC device. Recently ruthenium(II) complexes with the alkyl substituted aryl moieties directly connected to
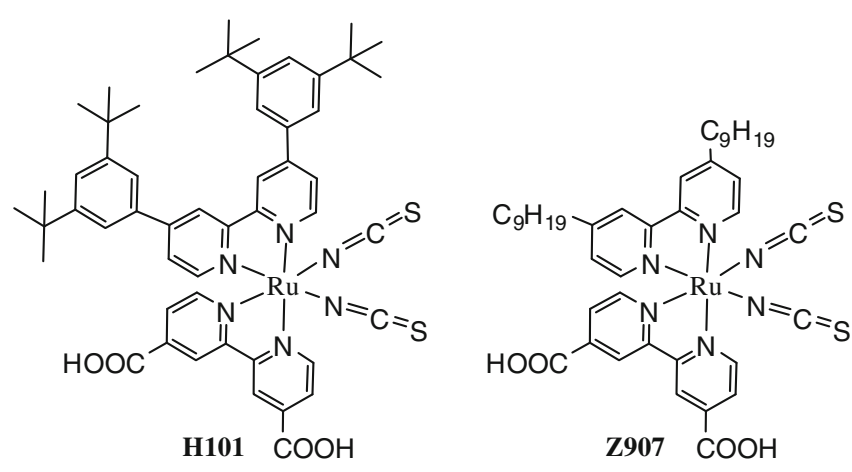

Figure 1. Structure of $\mathbf{H} 101$.

bipyridines as ancillary ligand have shown substantial improvement in the solar-to-electrical energy conversion efficiency ${ }^{16,44,45}$ and it seems to be reasonable to explore further these non-vinylogous structures for achieving better overall performance in photovoltaic devices. In this regard, a new ancillary bipyridyl ligand 4,4'-bis(3,5-di-tert-butylphenyl)-2,2'-bipyridine (L1) was designed (figure 1) and synthesised by coupling the corresponding 3,5-di-tert-butylphenylboronic acid with 4,4'-dibromo-2,2'-bipridine under palladium catalysed Suzuki conditions. ${ }^{46,47}$ This ligand was successfully employed to synthesize the corresponding polypyridyl ruthenium(II) complex 'cis-Ru(L1) (4,4'-dicarboxylic acid-2,2'-bipyridine)(NCS) $)_{2} \mathbf{H} 101$ '. In this paper, we presented the synthesis and the photovoltaic characteristics of $\mathbf{H} 101$ sensitized solar cell fabricated with an active area of $0.54 \mathrm{~cm}^{2}$ dye sensitized $\mathrm{TiO}_{2}$ electrodes in conjunction with ionic liquid electrolyte. The photovoltaic characteristics of the sensitizer were compared with reference $\mathbf{Z 9 0 7}$ cell fabricated and measured under identical conditions.

\section{Experimental}

\subsection{General}

1-bromo-3, 5- di-tert-butyl benzene, $n$-BuLi, $\mathrm{Pd}\left(\mathrm{PPh}_{3}\right)_{4}$, $\mathrm{NH}_{4} \mathrm{NCS}$, 1,2-dimethyl-3- $n$-propylimidazolium iodide (DMPII), 4-tert-butylpyridine (TBP), hexachloroplatinic acid, tetrabutylammoniumhydroxide (TBA) were purchased from Sigma-Aldrich. 4,4'-dibromo 2,2'bipyridine was procured from Heterocycles and Catalysts, Gundeldingerstrasse 174, CH-4053 Basel, Switzerland. Sephadex LH-20 was procured from GE Healthcare Bio-Sciences AB, SE-75184, Uppsala. Dichloro ( $p$-cymene) ruthenium (II) dimer and 2,2'bipyridine-4,4'-dicarboxylic acid were prepared in accordance to the reported procedures. ${ }^{48,49}$ All solvents 
and reagents, unless otherwise stated, were of Laboratory Reagent Grade and used as received. Brucker 300 Avance ${ }^{1} \mathrm{H}$ NMR spectrometer, Shimadzu LCMS2010EV model with ESI probe, Shimadzu UV-Vis spectrometer (Model: UV-1700) and Fluorolog 3, J.Y. Horiba Fluorescence spectrometers were employed to characterize 4,4'-bis(3,5-ditert-butylphenyl)-2,2'bipyridine, and the new polypyridyl ruthenium(II) complex (H101). 4, 4'-dinonyl-2,2'-bipyridine (L2) was procured from Sigma-Aldrich.

2.1a Synthesis of 3, 5-di-tert-butylphenylboronic acid: To a stirring cooled $\left(-78^{\circ} \mathrm{C}\right)$ solution of 1-bromo3, 5-di-tert-butyl benzene $(500 \mathrm{mg}, 1.858 \mathrm{mmol})$ in dry tetrahydrofuran, $n$-BuLi $(1.394 \mathrm{ml}, 1.6 \mathrm{M}$ in hexane) was added drop-wise under nitrogen atmosphere. After stirring continued for $1 \mathrm{~h}$, triisopropyl borate $(0.642 \mathrm{ml}, 2.787 \mathrm{mmol})$ was added at the same temperature. The reaction mixture was further stirred for $2 \mathrm{~h}$, and quenched with water followed by $6 \mathrm{M} \mathrm{HCl}$ solution drop-wise until $\mathrm{pH}$ dropped below 7.0. The resulting mixture was poured into water and then extracted with dichloromethane. The combined organic layers were dried over anhydrous sodium sulphate and after evaporation of dichloromethane under a reduced pressure, the resulting solid was purified by column chromatography on silica gel with dichloromethane/methanol (9/1) as eluent to afford 3,5-di-tert-butylphenylboronic acid (239 mg, 55\% yield).

${ }^{1} \mathrm{H}-\mathrm{NMR}\left(\delta \mathrm{H} / \mathrm{ppm}\right.$ in $\left.\mathrm{CDCl}_{3}\right): 7.45(\mathrm{~s}, 1 \mathrm{H}), 7.11(\mathrm{~s}$, $2 \mathrm{H}), 2.00(\mathrm{~s}, 2 \mathrm{H}), 1.40(\mathrm{~s}, 18 \mathrm{H})$. Chemical formula $\mathrm{C}_{14} \mathrm{H}_{23} \mathrm{BO}_{2}$, ESIMS: Calcd for $(\mathrm{M}+\mathrm{H})^{+}:$:234, found: 234.

2.1b Synthesis of 4,4'-bis(3,5-di-tert-butylphenyl)2,2'-bipyridine (L1): In a $25 \mathrm{ml}$ one-necked round bottom flask equipped with a condenser were placed corresponding boronic acid $(1.528 \mathrm{mmol})$, barium hydroxide octa-hydrade $(1.5 \mathrm{~g}, \quad 4.77 \mathrm{mmol})$ and palladium tetrakis triphenyl phosphine $(146 \mathrm{mg}$, $0.127 \mathrm{mmol}$ ). The reaction flask was evacuated and filled with nitrogen gas, then 1, 4-dioxane/water $(\mathrm{v} / \mathrm{v}$, $3: 1,8 \mathrm{ml}$ ) and 4,4-dibromo-2,2'-bipyridine $(200 \mathrm{mg}$, $0.636 \mathrm{mmol}$ ) were added. The reaction mixture was refluxed for $24 \mathrm{~h}$ under nitrogen gas and cooled to room temperature. The dioxane was removed and the contents were poured into dichloromethane, the precipitate formed was removed by filtration through filter paper and the organic layer was washed with $1.0 \mathrm{~m} \mathrm{NaOH}$ aqueous solution, and dried over sodium sulphate. After evaporation of dichloromethane under a reduced pressure, the resulting residue was diluted with a small quantity of methanol. The precipitate formed was immediately filtrated, dried and purified by column chromatography on silica gel with dichloromethane/methanol (9/1) as eluent to afford the corresponding ligand (447 mg, 55\% yield).

${ }^{1} \mathrm{H}-\mathrm{NMR}\left(\mathrm{CDCl}_{3}\right) 1.35(\mathrm{~s}, 9 \mathrm{H}), 6.82(\mathrm{~d}, 1 \mathrm{H}), 6.97$ (s, 2H), $7.30(\mathrm{~s}, 1 \mathrm{H}), 8.07(\mathrm{~s}, 1 \mathrm{H}), 8.50(\mathrm{~d}, 1 \mathrm{H})$; Chemical formula $\mathrm{C}_{38} \mathrm{H}_{48} \mathrm{~N}_{2}$, ESIMS: Calcd for $(\mathrm{M}+\mathrm{H})^{+}: 532$, found: 532 .

2.1c Synthesis of H101: Compound 4,4'- bis(3,5-ditert-butylphenyl) - 2,2'- bipyridine $(0.902 \mathrm{mmol})$ and dichloro ( $p$-cymene) ruthenium(II) dimmer $(276 \mathrm{mg}$, $0.451 \mathrm{mmol}$ ) in DMF were heated at $60^{\circ} \mathrm{C}$ for a period of $4 \mathrm{~h}$ under nitrogen in the dark. Subsequently, 4,4'-dicarboxylic acid-2, 2'-bipyridine $(220 \mathrm{mg}$, $0.902 \mathrm{mmol}$ ) was added and the reaction mixture was heated to $140^{\circ} \mathrm{C}$ for another $4 \mathrm{~h}$. To the resulting dark green solution was added solid $\mathrm{NH}_{4} \mathrm{NCS}(2.060 \mathrm{~g}$, $22.064 \mathrm{mmol}$ ) and the reaction mixture was further heated for 4 hours at $140^{\circ} \mathrm{C}$. After evaporation of DMF, water $(250 \mathrm{ml})$ was added to get precipitate. The purple solid was filtered off, washed with water and ether, and dried under vacuum. The crude compound was dissolved in methanol and dichloromethane and purified by column chromatography on Sephadex LH-20 with methanol/dichloromethane (3/2) as eluent to afford ruthenium complex (582 $\mathrm{mg}, 65 \%$ yield).

${ }^{1} \mathrm{HNMR}\left(\mathrm{CDCl}_{3}+\mathrm{CD}_{3} \mathrm{OD}\right) ; 1.31(\mathrm{~s}, 18 \mathrm{H}), 1.40(\mathrm{~s}$, $18 \mathrm{H}), 6.52(\mathrm{~d}, 1 \mathrm{H}), 6.89(\mathrm{~s}, 2 \mathrm{H}), 7.00(\mathrm{~d}, 1 \mathrm{H}), 7.15(\mathrm{~s}, 2 \mathrm{H})$, $7.20(\mathrm{~d}, 1 \mathrm{H}), 7.36(\mathrm{~s}, 1 \mathrm{H}), 7.50(\mathrm{~s}, 1 \mathrm{H}), 7.59(\mathrm{~s}, 1 \mathrm{H}), 7.73$ $(\mathrm{d}, 1 \mathrm{H}), 7.88(\mathrm{~s}, 1 \mathrm{H}), 7.98(\mathrm{~d}, 1 \mathrm{H}), 8.20(\mathrm{~d}, 1 \mathrm{H}), 8.80$ $(\mathrm{s}, 1 \mathrm{H}), 8.91(\mathrm{~s}, 1 \mathrm{H}), 9.20(\mathrm{~d}, 1 \mathrm{H}), 9.72(\mathrm{~d}, 1 \mathrm{H})$.

\subsection{Fabrication and photocurrent-voltage} measurements of the nanocrystalline $\mathrm{TiO}_{2}$ solar cells

The test cells were fabricated using $0.54 \mathrm{~cm}^{2}$ active area $\mathrm{TiO}_{2}$ electrodes in combination with $\mathrm{I}^{-} / \mathrm{I}_{3}^{-}$redox couple electrolyte. Initially the fluorine-doped $\mathrm{SnO}_{2}$ (FTO) conducting glass plates (Nippon Sheet Glass, $4 \mathrm{~mm}$ thick, $8 \Omega / \mathrm{sq}$ ) were cleaned with a detergent solution and then rinsed with water and ethanol to remove organics or any other contaminants, the dried glass plates were then treated in a $\mathrm{UV}_{-} \mathrm{O}_{3}$ system for 20 minutes. To facilitate a good mechanical contact between the nanocrystalline $\mathrm{TiO}_{2}$ and the conducting FTO matrix, the cleaned plates were treated with a $40 \mathrm{mM} \mathrm{TiCl}$ aqueous solution and then heated at $70^{\circ} \mathrm{C}$ for $30 \mathrm{~min}$ utes. Over the glass plate, $9 \mu \mathrm{m}$ thickness layer of $18 \mathrm{~nm}$ 
$\mathrm{TiO}_{2}$ particles (D18T) as transparent layer and then a $4.8 \mu \mathrm{m}$ thickness layer of $400 \mathrm{~nm}$ anatase $\mathrm{TiO}_{2}$ particles (CCIC, HPW-400) as scattering layer were successively laid one over the other. The electrodes coated with the $\mathrm{TiO}_{2}$ pastes were heated gradually under an air flow for 5 minutes each at $325^{\circ} \mathrm{C}$ and $375^{\circ} \mathrm{C}$ and for 15 minutes each at $450^{\circ} \mathrm{C}$ and $500^{\circ} \mathrm{C}$. The $\mathrm{TiO}_{2}$ electrodes were then allowed to cool and when the temperature attained around $100^{\circ} \mathrm{C}$, immersed in dye solutions of ethanol and remained soaked for 16 hours under dark. After taking out from the dye solutions, the electrodes were rinsed with ethanol to remove the un-adsorbed dye molecules and then dried under nitrogen gas. The counter electrodes were prepared by treatment of FTO glass plates (TEC 15, $2.2 \mathrm{~mm}$ thickness, Libbey-Owens-Ford Industries) with $\mathrm{TiCl}_{4}$ and further with a drop of $\mathrm{H}_{2} \mathrm{PtCl}_{6}$ solution ( $2 \mathrm{mg}$ of $\mathrm{Pt}$ in $1 \mathrm{~mL}$ of ethanol) and heated at $430^{\circ} \mathrm{C}$ for 15 minutes. The dye sensitized $\mathrm{TiO}_{2}$ electrode and Pt counter electrode were assembled into a sealed sandwich type cell by heating with a hot-melt surlyn film (Surlyn 1702, $25 \mu \mathrm{m}$ thickness, Du-Pont) as a spacer in-between the electrodes. The ionic liquid electrolyte was filled through the predrilled hole present on the counter electrode using vaccum filling technique, the hole was sealed with a Surlyn disk and a thin glass to avoid leakage of the electrolyte. The photo currentvoltage measurements of the DSSC devices fabricated were executed under the irradiation source of $450 \mathrm{~W}$ Xenon light (Osram XBO 450, U.S.A.), whose power was equivalent to AM 1.5 solar simulator. Prior to these measurements, the xenon light was calibrated by using a Tempax 113 solar filter (Schott) and the output power of the solar simulator was calibrated by using a reference Si photodiode equipped with a coloured matched IRcut-off filter (KG-3, Schott) to reduce the mismatch in the region of $350-750 \mathrm{~nm}$ between the simulated light and AM 1.5 to $<2 \%$. The measurement delay time of photo $\boldsymbol{I}-\boldsymbol{V}$ characteristics of DSSCs was fixed at $40 \mathrm{~ms}$. The incident light from a $300 \mathrm{~W}$ xenon lamp (ILC Technology, U.S.A.), which was focused through a Gemini-180 double monochromator (Jobin Yvon Ltd.), was employed to plot incident photon-to-current conversion efficiency as a function of excitation wavelength.

\section{Results and discussion}

\subsection{Synthesis}

The new polypyridyl ruthenium(II) complex, H101 (figure 1) was synthesized in accordance to the sequence of steps illustrated in Scheme 1. 1-bromo3,5-di-tert-butylbenzene was subjected to brominelithium exchange reaction using $n$-butyllithium in the presence of tri-isopropyl borate to give 3,5-ditert-butylphenylboronic acid, which was reacted with 4,4'-dibromo-2,2'-bipyridine under $\mathrm{Pd}(\mathrm{PPh} 3)_{2} \mathrm{Cl}_{2}$ catalysed Suzuki conditions to afford '4,4'-bis(3,5-ditert-butylphenyl)-2,2'-bipyridine'(L1). The reaction of $\left[\mathrm{RuCl}_{2} p \text {-cymene }\right]_{2}$ and $\mathbf{L} 1$ in DMF followed by addition of 2,2'-bipyridine-4,4'-dicarboxylic acid and excess ammonium thiocyanate finally afforded the ruthenium complex. The crude dried compound was purified on Sephadex LH20 column chromatography using methanol/dichloromethane $(1 / 1 \mathrm{~V} / \mathrm{V})$ mixture as eluent. The bipyridine ligand $\mathbf{L} 1$ and the ruthenium(II) complex, H101 have been fully characterised with ${ }^{1}$ HNMR, FT-IR and ESI-MASS Spectroscopies (figures S1 to S5 in the Supporting Information). The FTIR spectra (figure S7) of H101 show the bands at around $1610 \mathrm{~cm}^{-1}$ and $1383 \mathrm{~cm}^{-1}$ for the asymmetric and symmetric stretching modes of the carboxylate groups. The stretching bands at around $2100 \mathrm{~cm}^{-1}$ correspond to NCS groups indicating that NCS coordinated to the ruthenium center through the $\mathrm{N}$-atom. The stretching bands at around 2961 to $2865 \mathrm{~cm}^{-1}$ correspond to the aryl-tert-butyl groups, while the absorption bands at 1540 and $1463 \mathrm{~cm}^{-1}$ are ascribed to bipyridyl modes. The larger broad stretching band

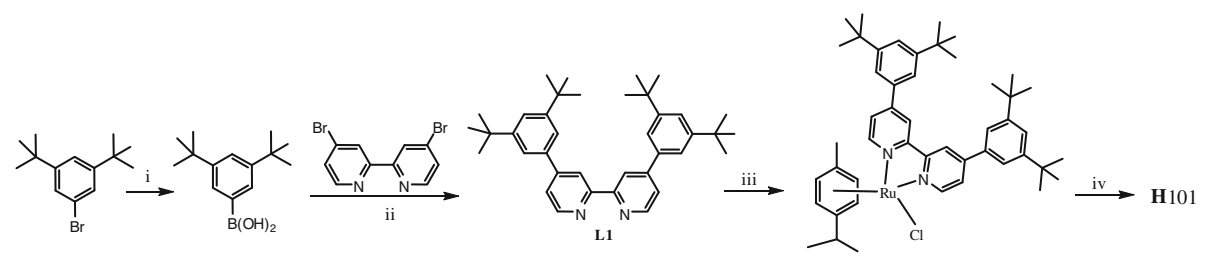

Scheme 1. Synthesis of H101 sensitizer. i) Tri-isopropylborate, n-BuLi, THF, at $-78^{\circ} \mathrm{C}, 2 \mathrm{M} \mathrm{HCl}$; ii) $\mathrm{Ba}(\mathrm{OH})_{2} .8 \mathrm{H} 2 \mathrm{O}, \mathrm{Pd}\left(\mathrm{PPh}_{3}\right)_{4}$, Dioxane: $\mathrm{H}_{2} \mathrm{O}$, reflux for $24 \mathrm{~h}$; iii) Ru- $p$-cymene complex, DMF, reflux for 12 h; iv) 2,2'-bipyridine-4,4'-dicarboxylic acid, $\mathrm{NH}_{4} \mathrm{NCS}, \mathrm{DMF}$, reflux for $12 \mathrm{~h}$. 
centered at $3397 \mathrm{~cm}^{-1}$ is due to the moisture adsorbed by the dye. The reference ruthenium(II) complex, cis-Ru(4,4'-dinonyl-2,2'-bipyridine)(4,4'-dicarboxylic acid-2,2'-bipyridine))(NCS) ${ }_{2}$ (Z907) was synthesized in accordance to the reported procedure. ${ }^{18}$

\subsection{Electronic absorption, emission and electrochemical properties of the dyes}

Equi-molar dye solutions of H101 and Z907 were prepared in ethanol and their comparative electronic absorption spectra recorded as a function of wavelength is shown in figure 2. The molar absorptions were recorded at $\mu \mathrm{M}$ dye concentrations, which are highly dilute as compared to those employed for staining the $\mathrm{TiO}_{2}$ electrodes. H101 shows well-defined two intense metal-to-ligand charge transfer transition (MLCT) absorption bands one in short wavelength region and the other one in long wavelength region. The molar extinction coefficient $(\varepsilon)$ of low-energy absorption band of $\mathbf{H} 101$ is $15000 \mathrm{M}^{-1} \mathrm{~cm}^{-1}$ at $531 \mathrm{~nm}$, while the reference sensitizer, $\mathbf{Z} 907$, showed $\varepsilon$-value of $10,800 \mathrm{M}^{-1} \mathrm{~cm}^{-1}$ at $540 \mathrm{~nm}$. Although, the MLCT absorption bands are blue shifted significantly in the high-energy region, as compared to those of $\mathbf{Z 9 0 7 ,}$ the sensitizer showed relatively $1 / 3$ improvement in molar absorptivity across the spectral range of 400 $750 \mathrm{~nm}$. Besides the molar extinction coefficient, the light-harvesting ability of DSSCs are also influenced by the optical absorptivity of sensitizer anchored on mesoporous $\mathrm{TiO}_{2}$ electrodes, which indirectly depend on molecular geometry and size. The absorption

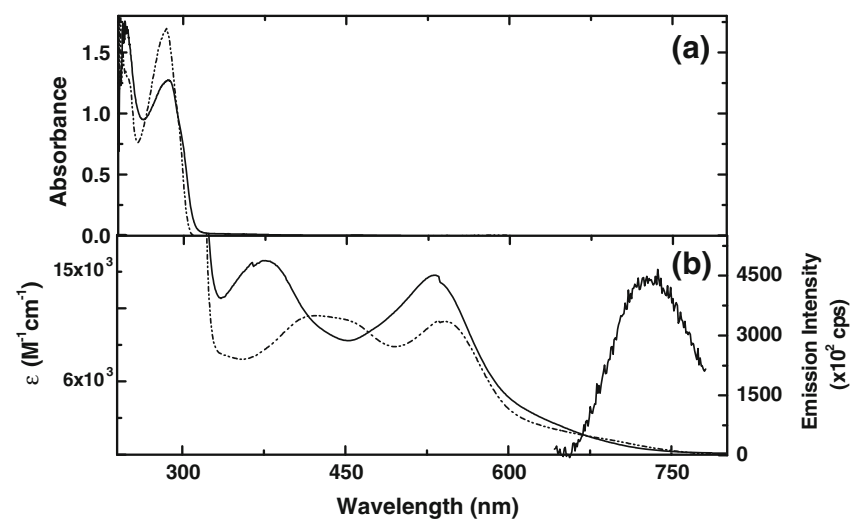

Figure 2. (a) Equi-molar absorption spectra of (-) 4,4'bis(3,5-di-tert-butylphenyl)-2,2'-bipyridine and (..-..) 4,4'dinonyl-2,2'-bipyridine in DMF. (b) Electronic absorption spectra of (-) H101 and (..-.) Z907 sensitizers in DMF medium. measurements of the dye coated on $\mathrm{TiO}_{2}$ electrodes were carried out by staining $7.0 \mu \mathrm{m}$ thick $\mathrm{TiO}_{2}(18 \mathrm{NRT}$ layered) films in the $0.3 \mathrm{mM}$ dye solutions for a period of $16 \mathrm{~h}$ under dark. The absorption spectra of $\mathbf{H} 101$ dye coated $\mathrm{TiO}_{2}$ film is compared with that of $\mathbf{Z} 907$. Figure S8 (Supporting Information) indicates that the dye molecules are anchored on $\mathrm{TiO}_{2}$ surface. The film absorbance ratio of $\mathbf{H 1 0 1}$ sensitizer (0.936) calculated by dividing the absorption maxima of H101 (0.9299) with the absorption maxima of $\mathbf{Z} 907$ sensitizer (0.9935) is relatively lower and indicates lower packing density of $\mathbf{H} 101$ on $\mathrm{TiO}_{2}$ surface. The substitution of 4, 4'bis(3,5-di-tert-butylphenyl) on the ancillary bipyridine in H101 increases the diagonal size of the dye molecule as predicted resulting in lower packing density of the dye on the $\mathrm{TiO}_{2}$ surface. ${ }^{50}$

In DSSCs, favourite energy offset between dye and titania is an essential requirement for achieving highefficiency, in which the sensitizer's immediate charge generation yield from the excited state has a direct influence on the device operation. The redox potentials of H101 were scrutinized with cyclic voltammetry using tetra-butyl ammonium perchlorate $(0.1 \mathrm{~m}$ in acetonitrile) as an electrolyte and ferrocene as an internal standard at $0.42 \mathrm{~V}$ vs SCE. Figure S9 (supporting information) shows the cyclic voltammogram of H101 measured in DMF solvent. The oxidation potential obtained for H101 sensitizer was 0.918 , while the reduction potential was $-0.810 \mathrm{vs}$ SCE. The more positive potential of this sensitizer, relative to $\mathrm{I}^{-} / \mathrm{I}_{3}^{-}$redox couple in the electrolyte, provide a large thermodynamic driving force for the regeneration of the dye by iodide. Based on absorption and emission spectra recorded in ethanol by exciting the complex with its corresponding lowenergy absorbance maximum, the excitation transition energy $\left(E_{0-0}\right)$ of $\mathbf{H} 101$ was estimated to be $1.85 \mathrm{eV}$ and the standard potential $\left(\phi^{0}\left(\mathrm{~S}+/ \mathrm{S}^{*}\right)\right)$, calculated from the relation of $\left[\phi^{0}(S+/ S)=\phi^{0}\left(S+/ S^{*}\right)-E 0-0\right]$, was $-0.9341 \mathrm{~V}$ vs SCE. So, $\phi^{0}\left(\mathrm{~S}+/ \mathrm{S}^{*}\right)$ value of the H101 dye is more negative (or higher in energy) than the conduction band edge of $\mathrm{TiO}_{2}$, providing a thermodynamic driving force to inject electron from the dye to $\mathrm{TiO}_{2}$.

\subsection{Computational studies}

To understand the increase in molar extinction coefficient augment with extension of $\pi$-conjugation through 4,4'-bis(3,5-di-tert-butylphenyl)-2,2'-bipyridine (L1) in H101, DFT geometry optimization and Time Dependent DFT excited state calculations for electronic 


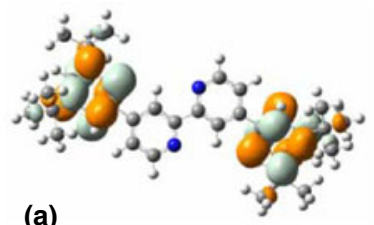

(a)

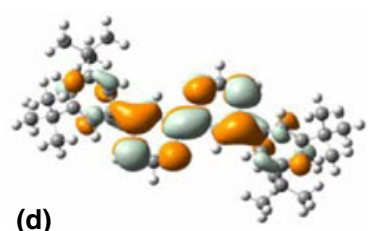

(d)

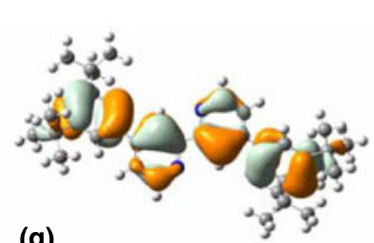

(e)

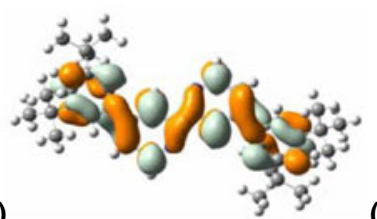

(c)
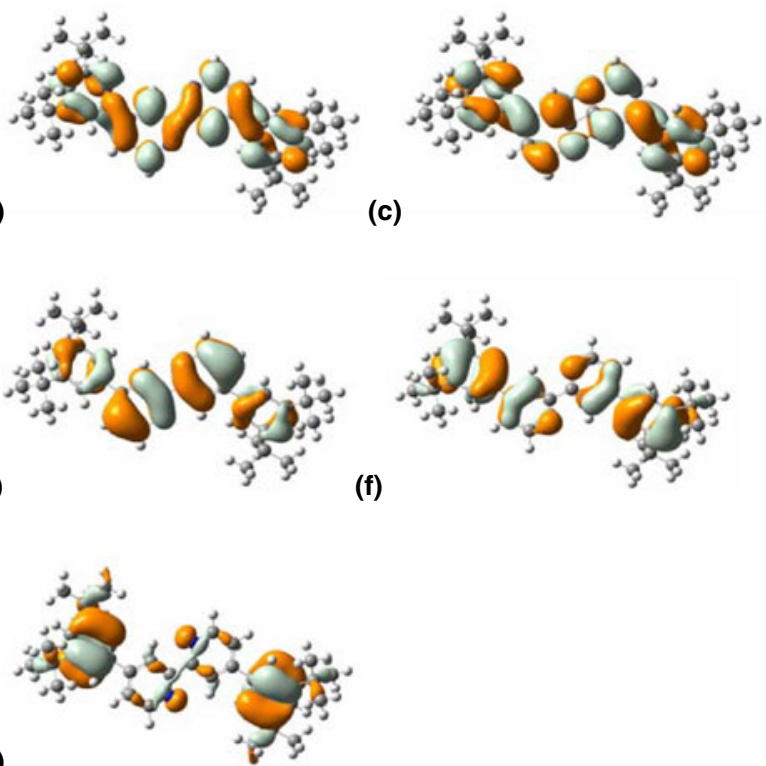
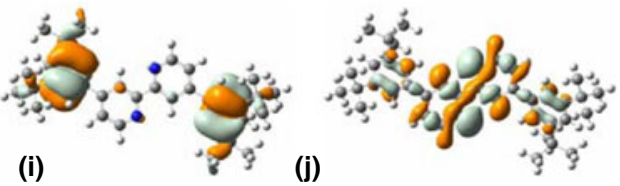

(k)

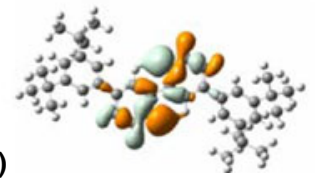

Figure 3. Transition involved molecular orbitals of ancillary ligand L1 of H101: (a) LUMO+3; (b) LUMO+2; (c) LUMO+1; (d) LUMO; (e) HOMO; (f) HOMO-1; (g) HOMO-2; (h) HOMO-3; (i) HOMO-4; (j) HOMO-5; (k) HOMO-6.

ground states of $\mathbf{L} 1,4,4$ ' -dinonyl-2,2'-bipyridine (L2), protonated ruthenium(II) complexes (H101 and Z907) were performed by using $\mathrm{mPW}(\mathrm{mPWx}+\mathrm{PW} 91 \mathrm{c})$ parameterization method. The combination of the Perdew-Wang 1991 exchange functional and modified by Adamoand Barone (mPWx) with the Perdew and Wang's 1991 gradient corrected correlation functional (PW91c) being developed along with mixed basis, LANL2DZ for ruthenium and 6-31G(d) basis for other atoms have been used in Gaussian 03. ${ }^{51}$ The transition involved frontier molecular orbitals (HOMO-6 to HOMO and LUMO to LUMO+3) of $\mathbf{L} 1$ are shown in figure 3, while those of $\mathbf{L} 2$ (HOMO-4 to HOMO and LUMO to LUMO+3) are shown in figure $\mathrm{S} 10$ in the Supporting Information. The HOMO-6 and HOMO7 orbitals of $\mathbf{L} 1$ resemble HOMO-1 and HOMO-2 orbitals of $\mathbf{L} 2$ and their energy levels shown in figure 5 are found to be close to one another. The $\pi$-orbitals corresponding to HOMO-1 to HOMO-3 of $\mathbf{L} 1$ are delocalized among the phenyl units $(\pi$-system) and pyridines, while LUMO to LUMO+3 orbitals have more $\pi^{*}$-orbital delocalization and the corresponding energy levels are depressed as compared to those of L2. The electronic absorption spectra recorded at equimolar concentration (figure 2a) showed lower molar absorptivity along with bathochromic shift by $6 \mathrm{~nm}$ for $\mathbf{L} 1$ relative to $\mathbf{L} 2$. The TD-DFT excitation calculations of these ancillary ligands showed lower oscillation strength for $\mathbf{L} 1$ with bathochromic shift by around $10 \mathrm{~nm}$ (table S1, Supporting Information) which indicate that the predictions of photophysical properties are close to the experimental observations.

Ancillary ligands with various extended $\pi$ conjugation systems in the ruthenium(II) complexes are known to improve $\varepsilon$-value along with significant bathochromic shift. To predict the influence of 3,5-di-tert-butyl phenyl as $\pi$-conjugation extension, the occupied and unoccupied frontier orbitals of $\mathbf{H 1 0 1}$ are shown in figure 4, while those of $\mathbf{Z} 907$ are compared (figure S11, Supporting Information). The first three occupied (HOMO to HOMO-2) orbitals of $\mathbf{H} 101$ exhibit ruthenium $t 2 \mathrm{~g}$ character, a sizeable contribution resulting from the mixing of thiocyanate ligand with $\pi$-bonding orbitals of 4,4'-bis(3,5-di-tert-butylphenyl)-2,2'-bipyridine and 4,4'-dicraboxylicacid-2,2'-bipyridine. The delocalized $\pi$-orbitals in HOMO to HOMO-2 orbitals of 4,4'bis(3,5-di-tert-butylphenyl)-2,2'-bipyridine favours size mixing with ruthenium(II)-NCS in H101 as compared to those in 4,4'-dinonyl-2,2'-bipyridine of $\mathbf{Z} 907$, which 

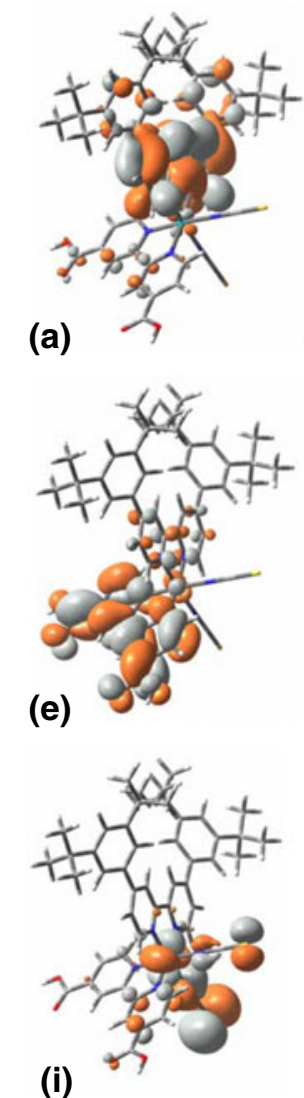

(f)

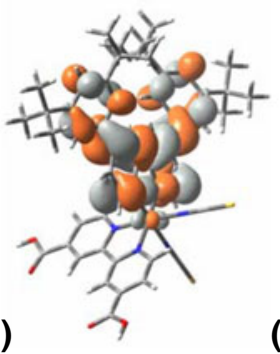

(b)
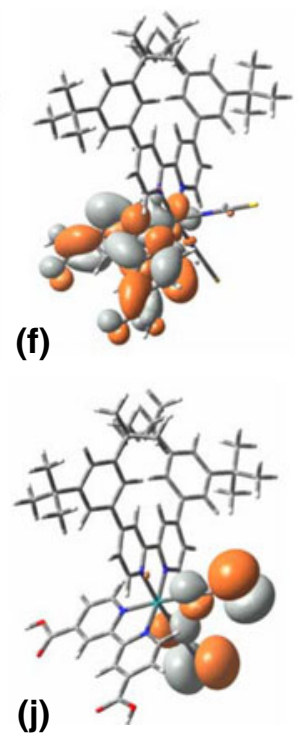
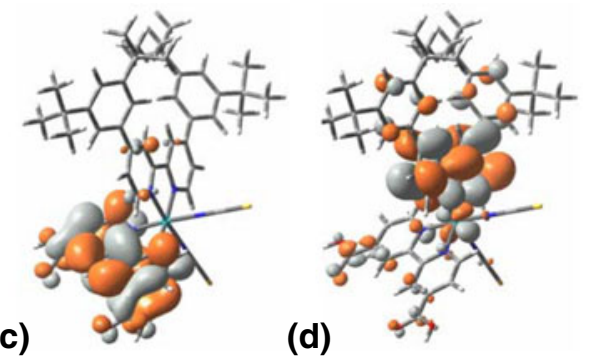

(d)
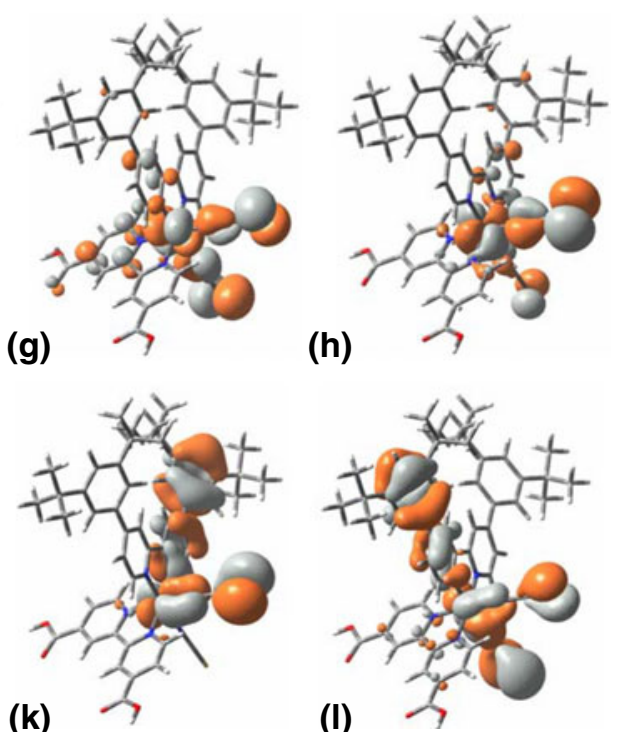

Figure 4. Frontier molecular orbitals of H101: (a) LUMO+5; (b) LUMO+4; (c) LUMO+3; (d) LUMO+2; (e) LUMO+1; (f) LUMO; (g) HOMO; (h) HOMO-1; (i) HOMO-2; (j) HOMO-3; (k) HOMO-4; (l) HOMO-5.

contributes to lift their energy levels. For Z Z907 and H101, the HOMO-3 orbitals are non-bonding combination localized on the NCS ligands. But relative to Z907 sensitizer, the increased molar extinction coefficient of $\mathbf{H} 101$ could be attributed to the lifted HOMO energy level. The HOMO-4 and HOMO-5 of H101 are combinations of two $\pi$-bonding orbitals of L1 with significant size mixing from NCS ligands and ruthenium centre, lift their energy levels. In case of the LUMO orbitals, it is noted that there is no obvious variation because of the sole distribution moved towards 4,4'-dicarboxylic acid-2,2'-bipridine and assuming similar molecular orbital geometry when adsorbed on $\mathrm{TiO}_{2}$ surface, the close position of the LUMO to the anchoring moieties will enhance overlap with the $3 \mathrm{~d}$ orbitals of $\mathrm{TiO}_{2}$ leading to facile electron injection. In case of higher unoccupied molecular orbitals of ancillary bipyridyl ligand, $\mathbf{L} 1$, the $\pi^{*}$-orbitals move from $\pi$-system to bipyridine moieties and these transfer in H101 sensitizer significantly depress the LUMO+4 and LUMO+5 orbitals and a moderate extending in case of LUMO+1 orbital relative to those of $\mathbf{Z} 907$.

\subsection{Photovoltaic performance of DSSCs based on the dyes}

To evaluate the performance of the new ruthenium(II) bipyridyl sensitizer, we employed a highquality double-layer titania film $(9.0+4.8 \mu \mathrm{m})$ and the most compatible electrolyte (Z580, containing $0.2 \mathrm{~m} \mathrm{I}_{2}, 0.5 \mathrm{~m}$ guanidinium thiocyanate and $0.5 \mathrm{~m}$ $\mathrm{N}$-metylbenzimidazole in a mixture of 1-propyl-3methylimidazolium iodide/1-ethyl-3-methyl imdazoliumtetracyanoborate $(65 / 35, \mathrm{v} / \mathrm{v}))$ to construct the test cells. Iodide-based ionic liquids are more viscous than conventional organic solvents. To reduce the viscosity of these electrolytes to some extent a binary ionic liquid electrolytes prepared by mixing iodide based ionic liquids (which can act both as a solvent and an iodide source) with low viscosity ionic liquids (having weakly coordinating anion based ionic liquids). The components in $\mathbf{Z 5 8 0}$ electrolyte meet the above requirements and apart from that Guanidinium thiocyanate in the redox electrolyte increases $\mathrm{V}_{\mathrm{OC}}$ by slowing recombination and also by inducing a downward 


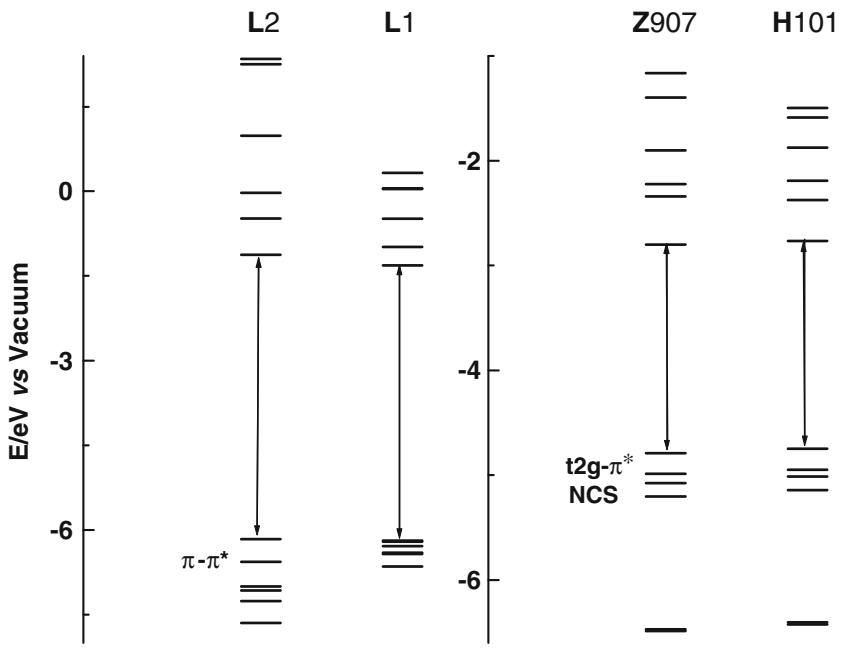

Figure 5. Energy diagram of occupied (HOMO to HOMO5 ) and unoccupied (LUMO to LUMO+5) frontier orbitals of 4,4'-bis(3,5-di-tert-butylphenyl)-2,2'-bipyridine (L1); 4,4'dinonyl-2,2'-bipyridine (L2), Z907 and H101 sensitizers.

shift of the $\mathrm{TiO}_{2}$ conduction band edge. ${ }^{52}$ The incident photon-to-current conversion efficiency (IPCE) of H101 sensitized DSSC plotted as a function of excitation wavelength (figure 6) showed broad plateau IPCE spectrum with IPCE exceeding $92.5 \%$. Considering the light absorption and scattering loss by the conducting glass, the absorbed photon-to-collected electron conversion efficiencies (APCE) are close to unity over a broad spectral range, suggesting a very high charge collection yield. To see the effect of light-harvesting enhancement due to increased $\pi$-conjugation extension, the photocurrent action spectrum of $\mathbf{H} 101$ was compared

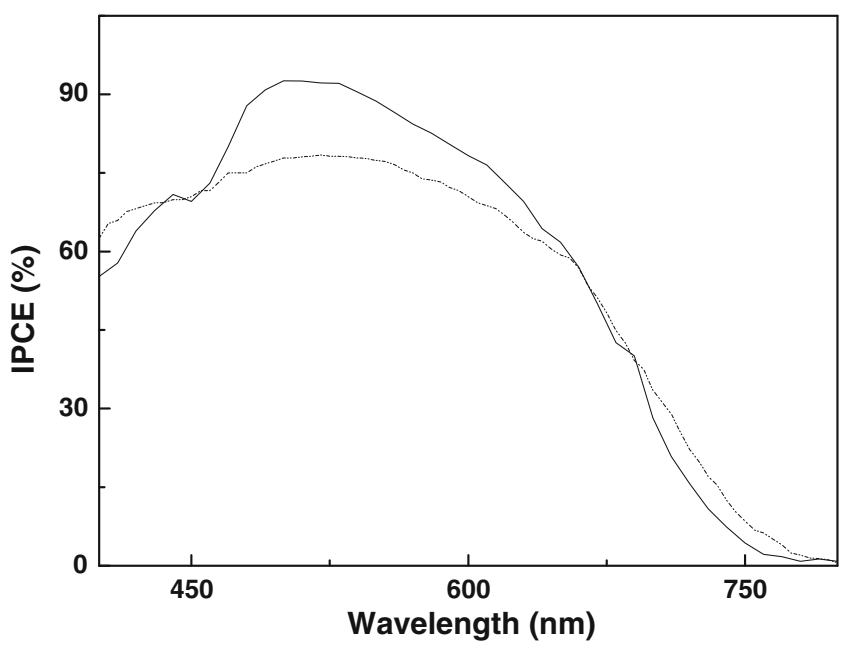

Figure 6. Photocurrent action spectra of devices of (-) H101 and (....) Z907 fabricated from $0.54 \mathrm{~cm}^{2}$ active area $\mathrm{TiO}_{2}$ electrodes sensitized in dye solutions of ethanol. with that of Z907 sensitized DSSC fabricated and evaluated under identical conditions. A lower IPCE value reaching $78.6 \%$ with broad plateau relatively red shifted as compared to $\mathbf{H} 101$ sensitizer was observed for $\mathbf{Z} 907$. Owing to the lower packing density of $\mathbf{H} 101$ over $\mathrm{TiO}_{2}$ surface, the $\mathbf{H} 101$ sensitized cell is expected to show a lower performance when compared to that of $\mathbf{Z} 907$ sensitized solar cell but the higher $\boldsymbol{J}_{\mathrm{SC}}$ of $\mathbf{H} 101$ could be probably favoured by more localized electron cloud over the 4,4'-dicarboxylic-2,2'-bypyridine in LUMO of H101 as compared to those in Z907 sensitizer. Figure 7 shows a typical photocurrent density-voltage curve of H101 sensitized solar cell measured under AM 1.5 sunlight illumination. The short-circuit photocurrent density $\left(\boldsymbol{J}_{\mathrm{SC}}\right)$, open-circuit voltage $\left(\boldsymbol{V}_{\mathrm{OC}}\right)$, and fill factor (ff) are $12.14 \mathrm{mAcm}^{2}, 690 \mathrm{mV}$ and 0.699 , respectively, yielding an overall energy conversion efficiency $(\eta)$ of $5.89 \%$, while the test device fabricated under identical conditions with $\mathbf{Z} 907$ dye gave $\boldsymbol{J}_{\mathrm{SC}}$ of $11.93 \mathrm{~mA} / \mathrm{cm}^{2}$, $\boldsymbol{V}_{\mathrm{OC}}$ of $650 \mathrm{mV}$, and ff of 0.666 yielding an overall energy conversion efficiency of $5.17 \%$.

One of the desirable parameters to retain the initial photovoltaic performance of the DSSC is the high thermal stability of the ruthenium(II) sensitizer. ${ }^{18}$ To see initially the influence of bis(3,5-di-tert-butylphenyl) substitution on the thermal stability of the new ruthenium(II) sensitizer, H101, TGA analysis was performed using a TGA/SDTA $851^{\mathrm{e}}$ thermal system (Mettler

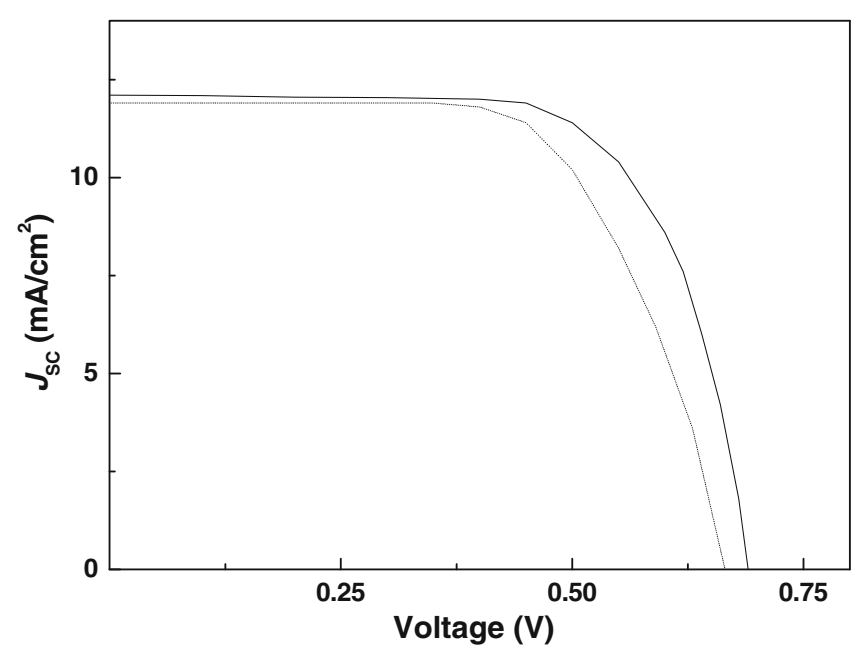

Figure 7. $\boldsymbol{J}-\boldsymbol{V}$ characteristics of (-) H101 and (..-..) Z907 cells (fabricated from $0.54 \mathrm{~cm}^{2}$ active area $\mathrm{TiO}_{2}$ electrodes), measured under an irradiance of $100 \mathrm{mWcm}^{-2}$ AM1.5G sun light. Double layer films $(9.0+4.8 \mu \mathrm{m})$. The electrolyte composition: $0.2 \mathrm{~m} \mathrm{I} 2,0.5 \mathrm{~m}$ guanidinium thiocyanate and $0.5 \mathrm{~m} \mathrm{~N}$-metylbenzimidazole in a mixture of 1-propyl-3-methylimidazolium iodide/1-ethyl-3-methylimdazoliumtetracyanoborate $(65 / 35, \mathrm{v} / \mathrm{v})$. 
Toledo, Switzerland) at heating rate of $10^{\circ} \mathrm{C} / \mathrm{min}$ in the temperature range of $25-600^{\circ} \mathrm{C}$ under $\mathrm{N}_{2}$ atmosphere (flow rate of $30 \mathrm{ml} / \mathrm{min}$ ). Film samples ranging from 8 to $10 \mathrm{mg}$ were placed in the sample pan and heated, while weight loss and temperature difference were recorded as a function of temperature. The thermo-gram thus obtained was compared with that of $\mathbf{Z} 907$. Figure S12(a) in supplementary information shows the derivative of per cent of conversion with respect to temperature, wherein both the thermo-grams of $\mathbf{H} 101$ and Z 907 initially follow similar trend and relatively extended thermal stability by another $30^{\circ} \mathrm{C}$ was observed for H101. In order to investigate further, the factors contributing for the increased thermal stability of the ruthenium(II) complex, the TGA analysis of ancillary ligands L1 and L2 are shown in figure S12(b) (supplementary information). The thermo-gram of $\mathbf{L} 2$ shows a transition at $420^{\circ} \mathrm{C}$, while that of $\mathbf{L} 1$ shows at around $470^{\circ} \mathrm{C}$ yielding an increase in thermal stability by $50^{\circ} \mathrm{C}$, which could be attributed to the conjugation of aromatic phenyl units against nonyl moieties on bipyridine. During the metal complex formation, these aromatic alkylsubstituted phenyl units have no effect on chelating bonds of ruthenium-bipyridine and thereby the substitution of 4,4'-bis(3,5-di-tert-butylphenyl)-2,2'-bipyridine in place of 4,4'-dinonyl-2,2'-bipyridine further stabilizes. This extended thermal stability is expected to improve the long term durability of photovoltaic performance of the sensitizer in DSSC.

The photovoltaic characteristics of H101 sensitized solar cell were measured at various temperatures by annealing the solar device in the pre-heated oven set at the desired temperature and were plotted as a function of temperature. Figure 8 shows a slight change in both $\boldsymbol{V}_{\mathrm{OC}}$ and fill factor across the temperature range of 30 to $80^{\circ} \mathrm{C}$, while a gradual increase in photo-current density, $\boldsymbol{J}_{\mathrm{SC}}$ was observed with increasing temperature of the device, which ultimately translated to gradual increase in the overall energy conversion efficiency. The photostability studies for these ruthenium(II) bipyridyl complexes were performed under a solar simulator at $100 \mathrm{mWcm}^{2}$ intensity. The $\mathbf{H} 101$ sensitized solar cell covered with an ultraviolet absorbing polymer film showed a nominal decrease in its initial $\eta$-value after $1,000 \mathrm{~h}$ of light-soaking at $55^{\circ} \mathrm{C}$. The aging tests have been performed at $55^{\circ} \mathrm{C}$ for $1000 \mathrm{~h}$ (figure 9), the power conversion efficiency of H101 sensitized solar cell was sustained even under heating, maintaining $85 \%$ of its initial value after this time period, while Z907 device retained $88 \%$ of its initial performance, despite the fact that the sustainability of the cell initial efficiency varies based on the type of electrolyte employed in the fabrication of DSSC. The retainability of initial efficiency for H101 sensitizer is slightly lower as compared to that of $\mathbf{Z} 907$. To understand this, a series of desorption studies of H101 and Z907 sensitized $\mathrm{TiO}_{2}$ films in $\mathrm{KOH}$-solutions were carried out separately to evaluate the desorption pattern of these dyes from $\mathrm{TiO}_{2}$ films. Though the results showed that desorption of $\mathbf{H} 101$ from $\mathrm{TiO}_{2}$ is quantitatively little more compared to that of $\mathbf{Z 9 0 7}$, the retainability of H101 sensitized solar cell is comparable with that of $\mathbf{Z 9 0 7}$ sensitizer and the relatively higher efficiency observed after complete aging of $1000 \mathrm{~h}$ at

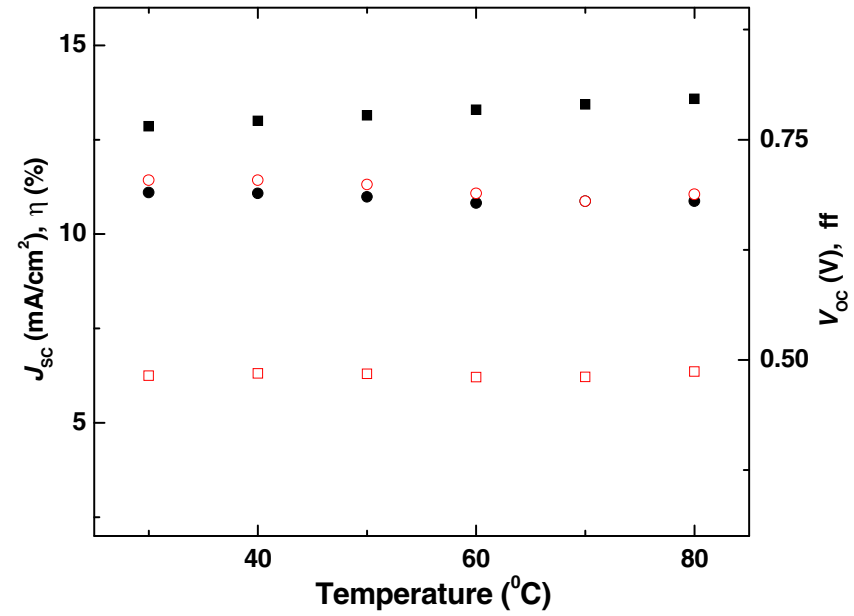

Figure 8. Detail of device parameter variations with temperature; ( $\square$ ) Short-circuit photocurrent density; ( $\square$ ) energy conversion efficiency; $(\bigcirc)$ open current voltage; (O) fill factor.

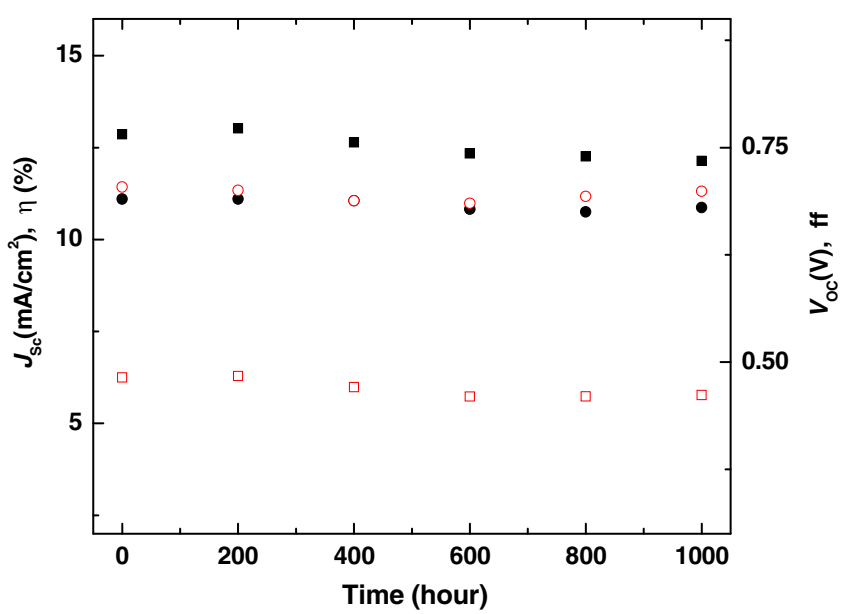

Figure 9. Details of device parameter variations for cells during accelerated aging at $50^{\circ} \mathrm{C} ;(\mathbf{\square})$ Short-circuit photocurrent density; ( $\square$ ) energy conversion efficiency; $(\bigcirc)$ open current voltage; (O) fill factor. 
$55^{\circ} \mathrm{C}$ is presumed to be resulting from the substitution of 4,4'-bis(3,5-di-tert-butylphenyl)-2,2'-bipyridine against 4,4'-dinonyl-2,2'-bipyridine in $\mathbf{Z} 907$ sensitizer. The main disadvantage of the $\pi$-extension $(\mathrm{C}=\mathrm{C}$ double bond) in ruthenium(II)-bipyridyl sensitizers is the slight catalysis of the electron/electrolyte recombination, which could be resulting through the vinylene spacers. The new ruthenium(II)-bipyridyl sensitizer, H101 is designed with exclusion of ethenyl spacers and the long-term device durability studies of the device indicate that the four tert-butyl groups on phenyl units of the ancillary bipyridyl ligand gives similar effect in terms of compatibility with ionic liquid electrolyte as observed with two $n$-nonyl groups of $\mathbf{Z} 907$.

\section{Conclusions}

To summarise, a high molar extinction coefficient ruthenium(II) sensitizer, exhibiting $5.89 \%$ power conversion efficiency for $0.54 \mathrm{~cm}^{2}$ active area DSSC under AM $1.5 \mathrm{G}$ conditions, has been synthesized using 4,4'-bis(3,5-ditert-butylphenyl)-2,2'-bipyridine as $\pi$ conjugated ancillary ligand. The TGA analysis of $\mathbf{H} 101$ showed relatively extended thermal stability, when compared to that of reference $\mathbf{Z} 907$ sensitizer. The sensitizer showed better incident photon-to-collected electron conversion efficiency and higher overall photovoltaic performance before and after completion of aging studies.

\section{Supplementary information}

The electronic supplementary information can be seen in www.ias.ac.in/chemsci.

\section{Acknowledgements}

Ch S R thanks Indian Institute of Chemical TechnologyAisin Cosmos (IICT-AIC) collaborative project for a fellowship. TS thanks Council of Scientific and Industrial Research (CSIR), New Delhi for senior research fellowship. MC thanks Department of Science and Technology (DST) New Delhi for the grant of the project entitled 'Advancing the efficiency and production potential of Excitonic Solar Cells (APEX)' under UK-DST consortium.

\section{References}

1. Benkstein K D, Kopidakis N, van de Lagemaat J, Frank A J 2003 J. Phys. Chem. B 1077759
2. Kumara G R A, Konno A, Shiratsuchi K, Tsukahara J, Tennakone K 2002 Chem. Mater. 14954

3. Hara K, Kurashige M, Ito S, Shinpo A, Suga S, Sayama K, Arakawa H 2003 Chem. Commun. 252

4. Ferrere S, Gregg B A 2001 J. Phys. Chem. B 1057602

5. Chen S G, Chappel S, Diamant Y, Zaban A 2001 Chem. Mater. 134629

6. Campbell W M, Burrell A K, Officer D L, Jolley K W 2004 Coord. Chem. Rev. 2481363

7. Nazeeruddin M K, Humphry-Baker R, Officer D L, Campbell W M, Burrell A K, Graetzel M 2004 Langmuir 206514

8. Reddy P Y, Giribabu L, Lyness Ch, Snaith H J, Vijaykumar $\mathrm{Ch}$, Chandrasekharam M, Lakshmikantam M, Yum J H, Kalyanasundaram K, Graetzel M, Nazeeruddin M K 2007 Angew. Chem., Int. Ed. 46373

9. Kuang D, Uchida S, Humphry-Baker R, Zakeeruddin S M, Graetzel M 2007 Angew. Chem. Int. Ed. 461949

10. Tatay S, Haque S A, O'Regan B, Durrant J R, Verhees W J H, Kroon J M, Vidal-Ferran A, Gavina P, Palomares E 2007 J. Mater. Chem. 173037

11. Giribabu L, Vijaykumar Ch, Reddy P Y, Yum J H, Graetzel M, Nazeeruddin M K 2009 J. Chem. Sci. 12175

12. Nazeeruddin M K, Angelis F D, Fantacci S, Selloni A, Viscardi G, Liska P, Ito S, Takeru B, Gratzel M 2005 J. Am. Chem. Soc. 12716835

13. Nazeeruddin M K, Pechey P, Renouard T, Zakeeruddin S M, Humphry-Baker R, Comte P, Liska P, Cevey L, Costa E, Shklover V, Spiccia L, Deacon G B, Bignozzi C A, Gratzel M 2001 J. Am. Chem. Soc. 1231613

14. Graetzel M 2005 Inorg. Chem. 446841

15. Jiang K J, Masaki N, Xia J B, Noda S, Yanagida S 2006 Chem. Commun. 422460

16. Chen C Y, Wu S J, Li J Y, Wu C G, Chen J G, Ho K C 2007 Adv. Mater. 193888

17. Hum J, Jung I, Nazeeruddin M K, Gratzel M 2009 Energy Environ. Sci. 2100

18. Wang P, Zakeeruddin S M, Moser J E, Nazeeruddin M K, Sekiguchi T, Gratzel M 2003 Nat. Mater. 2402

19. Wang P, Klein C, Humphry-Baker R, Zakeeruddin S M, Graetzel M 2005 J. Am. Chem. Soc. 127808

20. Kuang D, Klein C, Ito S, Moser J-E, Baker R H, Zakeeruddin S M, Gratzel M 2007 Adv. Funct. Mater. 17154

21. Kay A, Gratzel M 1996 Sol. Energy Mater. Sol. Cells 4499

22. Saito Y, Kitamura T, Wada Y, Yanagida S 2002 Chem. Lett. 311060

23. Suzuki K, Yamaguchi M, Kumagai M, Yanagida S 2003 Chem. Lett. 3228

24. Oskam G, Bergeron B V, Meyer G J, Searson P C 2001 J. Phys. Chem. B $\mathbf{1 0 5} 6867$

25. Nusbaumer $H$, Moser $J$-E, Zakeeruddin $S$ M, Nazeeruddin M K, Graetzel M 2001 J. Phys. Chem. B 10510461

26. Sapp S A, Elliott C M, Contado C, Caramori S, Bignozzi C A 2002 J. Am. Chem. Soc. 12411215

27. O' Regan B, Gratzel M 1991 Nature 353737

28. Nazeeruddin M K, Kay A, Rodicio I, Humphry-Baker R, Mueller E, Liska P, Vlachopoulos N, Graetzel M 1993 J. Am. Chem. Soc. 1156382 
29. Hagfeldt A, Gratzel M 2000 Acc. Chem. Res. 33 269

30. Gratzel M 2001 Nature $4 \mathbf{1 4} 338$

31. Papageorgiou N, Athanassov Y, Armand M, Bonhôte P, Pettersson H, Azam A, Grätzel M 1996 J. Electrochem. Soc. 1433009

32. Kohle O, Gratzel M, Meyer A F, Meyer T B 1997 Adv. Mater. 9904

33. Pettersson H, Gruszecki T 2001 Sol. Energy Mater. Sol. Cells. 70203

34. Kern R, van der Burg N, Chmiel G, Ferber J, Hasenhindl G, Hinsch Sommeling P, Späth M, Uhlendorf I 2000 Opto-Electron. Rev. 8284

35. Hinsch A, Koorn J M, Kern R, Uhlindorf I, Holzbock J, Meyer A, Ferber J 2001 Prog. Photovoltaics 9425

36. Pettersson H, Gruszecki T, Johansson L - H, Johander P 2003 Sol. Energy Mater. Sol. Cells 77405

37. Ajayaghosh A, Carol P, Sreejith S 2005 J. Am. Chem. Soc. 12714962

38. Sreejith S, Divya K P, Ajayaghosh A 2008 Chem. Commun. 442903

39. Divya K P, Sreejith S, Balakrishna B, Jayamurthy P, Aneesa P, Ajayaghosh A 2010 Chem. Commun. 466069

40. Giribabu L, Vijay Kumar Ch, Srinivasa Rao Ch, Gopal Reddy V, Yella Reddy P, Chandrasekharam M, Soujanya Y 2009 Energy Environ. Sci. 2770
41. Chandrasekharam M, Srinivasarao Ch, Suresh T, Anil Reddy M, Raghavender M, Rajkumar G, Srinivasu M, Yella Reddy P 2011 J. Chem. Sci. 12337

42. Chandrasekharam M, Rajkumar G, Srinivasa Rao Ch, Suresh T, Reddy P Y 2011 Syn. Met. 161 1469-1476

43. Chandrasekharam M, Rajkumar G, Srinivasa Rao Ch, Suresh T, Soujanya Y, Reddy P Y 2011 Adv. Optoelectronics (accepted). doi:10.1155/2011/432803

44. Chen R, Yang X, Tian H, Wang X, Hagfeldt A, Sun L 2007 Chem. Mater. 194009

45. Gao F, Wang Y, Shi D, Zhang J, Wang M, Jing X, Humphry-Baker R, Wang P, Zakeeruddin S M, Gratzel M 2008 J. Am. Chem. Soc. 13010720

46. Miyaura N, Suzuki A 1995 Chem. Rev. 952457

47. Li Z H, Wong M- S, Tao Y, Lu J 2005 Chem. Eur. J. 11 3285

48. Bennett M A, Huang T N, Matheson T W, Smith A K 1982 Inorganic Syntheses 2174

49. Gillaizeau I, Gauthier Odobel F, Alebbi M, Argazzi R, Costa E, Alberto Bignozzi C, Qu P, Meyer G J 2001 Inorg. Chem. 406073

50. Yu Q, Liu S, Zhang M, Cai N, Wang Y, Wang P 2009 J. Phys. Chem. C 11314559

51. Hay P J, Wadt W R 1985 J. Chem. Phys. 82299

52. Kopidakis N, Neale N R, Frank A J 2006 J. Phys. Chem. B 11012485 